\title{
Knowledge towards childhood immunization among mothers \& reasons for incomplete immunization
}

\author{
Vinodkumar Mugada ${ }^{*}$, Srujana Chandrabhotla, Divya Sai Kaja, Satya Gopala Krishna Machara \\ Aditya Pharmacy College, Department of Pharmacy Practice, ADB Road, Surampalem, East Godavari Dist., A.P., India.
}

\begin{tabular}{l} 
ARTICLE INFO \\
\hline Article history: \\
Received on: $12 / 07 / 2017$ \\
Accepted on: 20/09/2017 \\
Available online: $30 / 10 / 2017$ \\
\hline Key words: \\
Immunization, Knowledge, \\
gender disparity ratio, \\
incomplete immunization.
\end{tabular}

\section{INTRODUCTION}

There is no exaggeration to assert that vaccination is one of the greatest scientific discoveries ever made. It protects many children from getting sick and dead from dreadful diseases, thereby reducing the agony of many parents. So, there is necessity for the parents to develop unequivocal knowledge and perceptions about vaccinations. Because unequivocal knowledge and practices helps to develop positive attitude towards vaccination and thus their contribution to vaccination. It helps to reduce the burden of dreadful infectious diseases, which are best controlled by vaccination (Bruce et al., 2000, Omer et al., 2014). A positive correlation between parental knowledge, practice and vaccination rates of children was reported by many studies (Shah et al., 1991; Qidwai et al., 2007; Nath et al., 2008; Borras et al.,

\footnotetext{
* Corresponding Author

Vinodkumar Mugada, Aditya Pharmacy College, Department of

Pharmacy Practice, ADB Road, Surampalem, East Godavari Dist., A.P,

India. Email: mugadavinodkumar18@gmail.com
}

2009). Similarly many studies reported positive correlation between mother's knowledge, attitudes and practice and children's immunization (Nisar et al., 2010).

As shown in previous studies in resource limited settings, good immunization coverage has been achieved by the efforts of a robust primary health care approach (Bradley, IGALS, 2005) mothers' knowledge (Streatfield et al., 1990; Bhuiya et al., 1995; Bradley, IGALS, 2005) and the provision of immunization information (Bhuiya et al., 1995; Jamil et al., 1999; Cui and Gofin, 2007). Social Cognition Models have provided useful insight, particularly the fear of vaccine harm as a barrier to immunization (Peter et al., 2000).

Parental practices like unawareness of adverse effects and contraindications of vaccination, negative perceptions about vaccination in mild illness, negative attitude, for example, mother's fear of vaccination was considered as one of the major barrier to childhood vaccination (Gherardi, 2013). The belief that vaccines cause autism was the most prevalent parental concern in a survey conducted in the USA (Smith et al., 2009). 


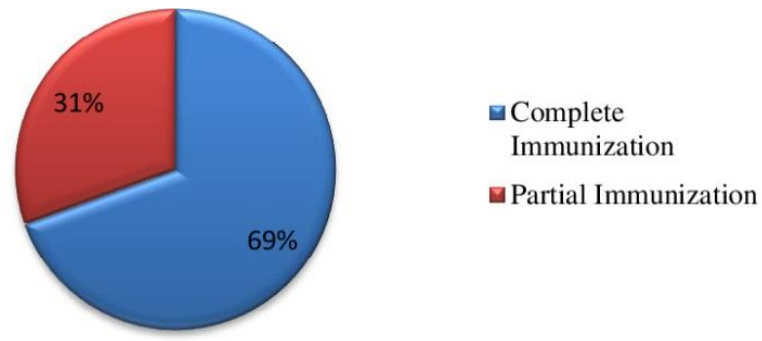

Fig. 1: Immunization status.

\section{MATERIALS AND METHODS}

This was a descriptive observational study and was conducted on 377 mothers for a duration of six months in the outpatient department of Pediatrics, Government General Hospital, Kakinada. The project was subject to approval by the Institutional Ethical Committee (RC.No.Clinicals/Pharma.D/N2/2016,Dt 22.04.2016). The study was conducted for a duration of 6 months starting from 22.04.2016 to 22.10.2016. After stating the aim and objective of research work clearly, an informed consent was taken from mothers who had shown their willingness to participate. Mothers with children of age below or equal to 3 years, mothers who visited the outpatient department of pediatrics were enrolled in the study. Mothers who did not cooperate for the interview, caretakers who brought children other than his/her mother was excluded from the study. A data collection form which suits our present study was framed. It contains demographic data like child's age, mother's age, location, and educational status, mother's occupation, etc. A qualitative interview was done using 20 mothers and based on their response questions was framed. Then a pilot study was carried out on 15 mothers. Cronbach's alpha coefficient test was applied to measure internal reliability (0.81) and thus a questionnaire was prepared to assess the knowledge of mothers on immunization. Immunization status of children was assessed from mothers or observed from the immunization card and reasons for incomplete vaccination was noted down. Knowledge assessment of mothers was carried out using a specially designed questionnaire. It consists of seven questions. Each question carries three options. Answering 'yes' to questions 1, 2, 3, 5, and 7 and 'no' to questions 4, 6 reveals good knowledge about immunization. The knowledge was categorized as poor $(\leq 0)$, fair $(1-5)$, good $(>5)$. Gender Disparity Ratio (GDR) was used to measure gender inequality in immunization. A GDR value of 100 indicates that there is no gender differential. GDR values exceeding 100 indicate that the girl child is at a disadvantage. Association between child gender, mother's occupation, mother's educational status, area of residence and birth order with immunization status was found using chi-square test. The association between mother's education, birth order with knowledge score was also found using chi-square test. $\mathrm{p}<0.05$ was considered as statistically significant.

\section{RESULT AND DISCUSSION}

The mean age of the mothers in the sample was $24.37 \pm 3.85$ years. Most of the mothers were unemployed
(90.18\%). Most of them completed graduation (38.9\%) followed by secondary education $(27.5 \%)$. Around $220(58.3 \%)$ are from urban set up (Table 1).

Table 1: Socio demographic characteristics of the sample ( $\mathrm{n}=377)$.

\begin{tabular}{|c|c|c|c|}
\hline $\begin{array}{l}\text { S. } \\
\text { No. }\end{array}$ & $\begin{array}{c}\text { Socio-demographics } \\
\text { characteristics }\end{array}$ & $\begin{array}{c}\text { Total } \\
\text { sample }\end{array}$ & $\begin{array}{c}\text { Percentage } \\
(\%)\end{array}$ \\
\hline \multirow[t]{5}{*}{1} & Age of Mother (in years) & & \\
\hline & $16-20$ & 59 & 15.65 \\
\hline & $21-25$ & 190 & 50.39 \\
\hline & $26-30$ & 100 & 26.52 \\
\hline & $31-35$ & 28 & 7.42 \\
\hline \multirow[t]{3}{*}{2} & Child gender & & \\
\hline & Male & 203 & 53.84 \\
\hline & Female & 174 & 46.15 \\
\hline \multirow[t]{3}{*}{3} & Occupation of Mother's & & \\
\hline & Unemployed & 340 & 90.18 \\
\hline & Working & 37 & 9.81 \\
\hline \multirow[t]{6}{*}{4} & Educational status of Mother's & & \\
\hline & Nil & 16 & 4.24 \\
\hline & Primary & 47 & 12.46 \\
\hline & Secondary & 98 & 25.99 \\
\hline & Inter & 74 & 19.62 \\
\hline & Degree & 142 & 37.66 \\
\hline \multirow[t]{3}{*}{5} & Area of Residence & & \\
\hline & Rural & 160 & 42.44 \\
\hline & Urban & 217 & 57.56 \\
\hline \multirow[t]{4}{*}{6} & Birth order of children & & \\
\hline & $1^{\mathrm{st}}$ & 213 & 56.49 \\
\hline & $2^{\text {nd }}$ & 155 & 41.11 \\
\hline & $3^{\text {rd }}$ & 9 & 2.38 \\
\hline
\end{tabular}

Table 2: Knowledge assessment criteria of total sample $(n=377)$.

\begin{tabular}{clccc}
\hline $\begin{array}{c}\text { S. } \\
\text { No. }\end{array}$ & $\begin{array}{c}\text { Knowledge assessment } \\
\text { questions }\end{array}$ & $\begin{array}{c}\text { Yes } \\
(\boldsymbol{\%})\end{array}$ & $\begin{array}{c}\text { No } \\
(\boldsymbol{\%})\end{array}$ & $\begin{array}{c}\text { Don't } \\
\text { know (\%) }\end{array}$ \\
\hline 1 & $\begin{array}{l}\text { Knowledge regarding age } \\
\text { related vaccination }\end{array}$ & 87.26 & 3.97 & 8.75 \\
2 & $\begin{array}{l}\text { Vaccine prevents diseases } \\
3\end{array}$ & 97.61 & 0.79 & 1.59 \\
& $\begin{array}{l}\text { Vaccination should be } \\
\text { given from birth }\end{array}$ & 97.08 & 1.59 & 1.32 \\
4 & $\begin{array}{l}\text { Vaccines are harmful } \\
5\end{array}$ & 2.65 & 93.10 & 4.24 \\
& $\begin{array}{l}\text { Child with common cold be } \\
\text { vaccinated }\end{array}$ & 15.64 & 59.41 & 24.93 \\
& $\begin{array}{l}\text { Child with fever be } \\
\text { vaccinated }\end{array}$ & 8.48 & 62.33 & 29.17 \\
& $\begin{array}{l}\text { Child with diarrhea be } \\
\text { vaccinated }\end{array}$ & 9.01 & 60.21 & 30.76 \\
\hline
\end{tabular}

Around 115 (30.50\%) children were partially immunized. Unavailability of vaccine was considered to be the major reason for incomplete immunization. Other reasons for incomplete immunization were unawareness of mother regarding age related vaccines, the child was ill-was brought and was not immunized, unawareness of need for immunization (Table 3).

Table 3: Reasons for incomplete immunization $(n=377)$.

\begin{tabular}{|c|c|c|c|}
\hline $\begin{array}{c}\text { S. } \\
\text { No. }\end{array}$ & Reasons for incomplete vaccination & 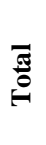 & 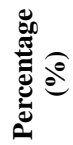 \\
\hline 1 & Mother was too busy & 4 & 1.06 \\
\hline 2 & There was a family problem & 5 & 1.32 \\
\hline 3 & The vaccine was not available & 52 & 13.79 \\
\hline
\end{tabular}




\begin{tabular}{llcc}
\hline 4 & The time for immunization was not convenient & 2 & 0.53 \\
5 & There was a postponement in going until another time & 4 & 1.06 \\
6 & The child was ill-was brought but not immunized & 12 & 3.18 \\
7 & The child was ill-was not brought & 6 & 1.59 \\
8 & Unaware of the need for a second or third dose & 0 & --- \\
9 & No belief in the vaccination & 0 & --- \\
10 & Was not aware of the need for immunization & 9 & 2.38 \\
11 & Mother was afraid of side effects & 0 & --- \\
12 & Mother was unaware of age related vaccination & 13 & 3.44 \\
13 & Did not know the place and time for immunization & 2 & 0.53 \\
14 & There was long queue and waiting time & 0 & --- \\
15 & Unaware of optional vaccines & 0 & -- \\
16 & Mother was asked to buy any vaccines & 6 & 1.59 \\
\hline
\end{tabular}

Table 4: Gender disparity ratio values.

\begin{tabular}{ccccc}
\hline S.No. & Gender & $\begin{array}{c}\text { Complete } \\
\text { Immunization } \\
\text { (in percentage) }\end{array}$ & $\begin{array}{c}\text { Partial } \\
\text { Immunization } \\
\text { (in percentage) }\end{array}$ & $\begin{array}{c}\text { Gender } \\
\text { Disparity } \\
\text { Ratio }\end{array}$ \\
\hline 1 & Male & 76.84 & 23.15 & 115.27 \\
2 & Female & 66.66 & 33.33 & \\
\hline
\end{tabular}

Table 5: Association between socio demographics and immunization status.

\begin{tabular}{|c|c|c|c|c|}
\hline \multirow{2}{*}{$\begin{array}{c}\text { Socio } \\
\text { demographic } \\
\text { Characteristic }\end{array}$} & \multicolumn{2}{|c|}{ Immunization Status } & \multirow[b]{2}{*}{ Statistic } & \multirow[b]{2}{*}{ p-value } \\
\hline & Complete & Partial & & \\
\hline \multicolumn{3}{|c|}{ Gender } & \multirow{3}{*}{$\chi^{2}=4.832$} & \multirow{3}{*}{$0.027^{*}$} \\
\hline Male & $156(76.84 \%)$ & $47(23.15 \%)$ & & \\
\hline Female & $116(66.66 \%)$ & $58(33.33 \%)$ & & \\
\hline \multicolumn{5}{|c|}{ Occupation } \\
\hline Unemployed & $247(72.64 \%)$ & $93(27.35 \%)$ & & \\
\hline Employed & $28(75.67 \%)$ & $9(24.32 \%)$ & $\chi^{2}=0.155$ & 0.693 \\
\hline \multicolumn{5}{|c|}{ Education } \\
\hline Nil & $11(68.75 \%)$ & $5(31.25 \%)$ & \multirow{5}{*}{$\chi^{2}=4.645$} & \multirow{5}{*}{0.325} \\
\hline Primary & $37(78.72 \%)$ & $10(21.27 \%)$ & & \\
\hline Secondary & $69(70.40 \%)$ & $29(29.59 \%)$ & & \\
\hline Inter & $60(81.08 \%)$ & $14(18.91 \%)$ & & \\
\hline Degree & $98(69.01 \%)$ & $44(30.98 \%)$ & & \\
\hline \multicolumn{5}{|c|}{ Area of Residence } \\
\hline Rural & $120(75 \%)$ & $40(25 \%)$ & & \\
\hline Urban & $153(70.50 \%)$ & $64(29.49 \%)$ & $\chi^{2}=1.067$ & 0.301 \\
\hline \multicolumn{5}{|c|}{ Birth Order } \\
\hline 1 & $160(75.11 \%)$ & $53(24.88 \%)$ & \multirow{3}{*}{$\chi^{2}=4.009$} & \multirow{3}{*}{0.134} \\
\hline 2 & $110(70.96 \%)$ & $45(29.03 \%)$ & & \\
\hline 3 & $3 \quad(33.33 \%)$ & $6(66.66 \%)$ & & \\
\hline
\end{tabular}

The association between gender and immunization status was found to be statistically significant $(p=0$. 027), while associations between other demographic variables, like mother's occupation, mother's education, area of residence and birth order with immunization status was found to be statistically not significant (Table 5).

Some studies reported that girls are less likely to access immunization than boys (Filmer et al., 1998; Fikree, Pasha, 2004). Gender discrimination in immunization coverage has been shown to exist in all states of India (Pande, Yazbeck, 2003; Borooah, 2004). These studies depicted that female children are subjected to gender discrimination and are not getting proper attention regarding immunization. Few other studies also depicted same difference, but were insignificant (Moulton et al., 2005; Elliott, Farmer, 2006). The evidence from recent national level data shows that the gender gap in full immunization coverage has either stagnated or narrowed (Gaudin, Yazbeck, 2006; Bhagyalaxmi et al., 2007). Trend analysis shows that, at the national level, the average gender disparity in full immunization has remained constant (Prusty, Kumar, 2014).

Gender differentials are calculated as a simple ratio of immunization rates for boys and girls, multiplied by 100 , as follows:

Gender disparity ratio (GDR) for full immunization:

$$
\begin{aligned}
& =\frac{\% \text { of boys fully immunized }}{\% \text { of girls fully immunized }} \times 100=\frac{76.84 \%}{66.66 \%} \times \\
& 100=115.27(\text { Table } 4)
\end{aligned}
$$

A GDR for complete immunization (115.27) clearly indicates gender inequality in the present study (Pande, Yazbeck, 2003).

Mother's education influences health seeking behavior. It is also believed that higher the level of education, higher the proportion of children who were fully immunized. In the present study, the association between the mother's education and immunization status was found to be statistically not significant. Similar findings were reported in some other studies (Mabrouka, 2011; Félicitée et al., 2016). In contrast many studies have reported a statistically significant association between mother's education and immunization status (Bruce et al., 2000; Nath et al., 2008; Borras et al., 2009; and Soundarya et al., 2014). Perhaps, nationwide social welfare programmes like Integrated Child Development Services (ICDS) succeeded in bringing awareness in everyone by setting up anganwadi centers, a community based service- delivery division of ICDS. Electronic media also play a crucial role in bringing awareness about vaccination.

Area of residence and immunization status is not associated in present study (Table 5). But the Urban-rural inequality ratio of the present sample (94) also indicates no inequality in the coverage of full immunization. Urban-rural inequality ratio was calculated as a ratio of full immunization rates. Urban-Rural differentials are calculated as a simple ratio of immunization rates for urban and rural, multiplied by 100 , as follows:

Urban-Rural inequality ratio (URIR) for full immunization:

$$
\frac{\% \text { of urban children fully immunized }}{\% \text { of rural children fully immunized }} \times 100=\frac{70.50 \%}{75 \%} \times 100=94
$$

A value of 100 in an inequality ratio would imply that there was no urban-rural difference in full immunization coverage, while a value above 100 would indicate inequality in the coverage of full immunization. Specifically, geographical access has a greater impact on the utilization of health care services, particularly in rural areas with the limited service provision of health care services (Singh, 2013). Usually unemployed mothers have more feasibility towards child immunization than employed mothers.

Mother's occupation was not associated with immunization status in our study (Table 5). Similar findings were presented in other studies (Malini et al., 2001; Mabrouka, 2011). Some studies reported statistically significant association between mother's occupation and immunization status (Vilas et al., 2013; John, 2014). 
There are fewer chances of complete immunization for the first child than second and third one. Better awareness and improved knowledge about the benefits of immunization, availability of polyvalent vaccines which cures two or more diseases might be the reason. Birth order is not associated with immunization status in the present study (Table 5). Inverse relationship between birth order and immunization status was disclosed in some studies (Elizabeth et al., 2003; Bhola et al., 2007; Vilas et al., 2013). The association between mother's education and knowledge score was statistically significant in our study $(\mathrm{p}=0.005)$.

Many studies reported similar findings and significant association (Mabrouka, 2011; Fatima, Chizoma, 2013; Omer et al., 2014; Soundarya et al., 2014; and Chris et al., 2015). Uneducated mothers were less conscious about the immunization of their children as compared to the mothers who were highly educated. A statistically significant association was found between area of residence and knowledge score towards immunization in our study $(\mathrm{p}=0$. 001) (Table 6). However, recently nationwide service programs have been successful in bringing awareness about immunization in rural areas.

Anganwadi workers to ensure immunization for children below 6 years of age. Electronic media and mass media are also bringing awareness about immunization through advertisements and special programmes.

Table 6: Association of socio demographics with knowledge score.

\begin{tabular}{|c|c|c|c|c|c|}
\hline \multirow{2}{*}{$\begin{array}{c}\text { Socio } \\
\text { Demographic } \\
\text { Characteristic }\end{array}$} & \multicolumn{3}{|c|}{ Knowledge Score } & \multirow{2}{*}{ Statistic } & \multirow{2}{*}{$\begin{array}{c}\text { p- } \\
\text { value }\end{array}$} \\
\hline & Poor & Fair & Good & & \\
\hline \multicolumn{6}{|l|}{ Education } \\
\hline Nil & 2 & 13 & 25 & \multirow{5}{*}{$\chi^{2}=21.605$} & \multirow{5}{*}{$0.005^{*}$} \\
\hline Primary & 4 & 39 & 4 & & \\
\hline Secondary & 12 & 77 & 11 & & \\
\hline Inter & 4 & 58 & 5 & & \\
\hline Degree & 3 & 113 & 30 & & \\
\hline \multicolumn{6}{|l|}{ Birth order } \\
\hline $1^{\text {st }}$ child & 15 & 164 & 33 & \multirow{3}{*}{$\chi^{2}=3.291$} & \multirow{3}{*}{0.510} \\
\hline $2^{\text {nd }}$ child & 9 & 130 & 18 & & \\
\hline $3^{\text {rd }}$ child & 1 & 7 & 0 & & \\
\hline \multicolumn{6}{|c|}{ Area of residence } \\
\hline Rural & 20 & 110 & 23 & \multirow{2}{*}{$\chi^{2}=28.019$} & \multirow{2}{*}{$0.001^{\prime}$} \\
\hline Urban & 85 & 116 & 23 & & \\
\hline \multicolumn{6}{|c|}{ Immunization Status } \\
\hline Complete & 17 & 216 & 33 & \multirow{2}{*}{$\chi^{2}=1.048$} & \multirow{2}{*}{0.591} \\
\hline Partial & 7 & 85 & 18 & & \\
\hline
\end{tabular}

\section{CONCLUSION}

Gender disparity in immunization was observed in our study. In contrary to many studies, no association was found between immunization status of children and area of residence, Birth order, or mother's education. Mother's education and area of residence were found to get associated with knowledge of immunization. However, knowledge towards immunization and immunization status was not significantly associated. It shows a very good progression regarding awareness of immunization. Issues regarding gender disparity should be addressed. In recent days electronic media and anganwadi worker's efforts in raising consciousness about the importance of immunization might increase the immunization rate irrespective of knowledge and area of residence of people.

\section{Financial support and sponsorship: Nil.}

Conflict of Interests: There are no conflicts of interest.

\section{REFERENCES}

Bhagyalaxmi A, Kedia G, Rawal VS . Study of incidence of measles and vaccination coverage in Ahmedabad urban slums. Indian Journal of Public Health, 2007; 51: 52-53.

Bhola Nath, J. V. Singh, Shally Awasthi, Vidya Bhushan, Vishwajit Kumar, S. K. Singh. A study on determinants of immunization coverage among 12-23 months old children in urban slums of Lucknow district, India. Indian J Community Med, 2007; 32(4): 96-100.

Bhuiya A, Bhuiya I, Chowdhury M. Factors associating acceptance of immunization among children in rural Bangladesh. Health Policy Plan, 1995; 10: 304-311.

Borràs E, Domínguez A, Fuentes M, Batalla J, Cardeñosa N, Plasencia A. Parental knowledge of paediatric vaccination. BMC Public Health, 2009; 9:154.

Borooah V. Gender bias among children in India in their diet and immunization against disease. Social Science and Medicine, 2004; 58: $1719-1731$

Bradley J, IGALS S. Improving the quality of child health services: participatory action by provinces. Int J Qual Health Care, 2005; 17:391-399.

Bruce G. Gellin, Edward W. Maibach, and Edgar K. Marcuse. Do parents understand immunizations? A national telephone survey. Pediatrics, 2000; 106 (5): 1097-1102.

Chris-Otubor, G.O., Dangiwa, D.A., Ior, L.D, Anukam, N.C. Assessment of Knowledge, Attitudes and Practices of Mothers in Jos North Regarding Immunization. IOSR Journal Of Pharmacy, 2015; 5 (6): $34-45$.

Cui FQ, Gofin R. Immunization coverage and its determination in children aged 12-23 months in Gaunsu, China. Vaccine, 2007; 25: 664671.

Elizabeth T. Lumen, Steven B. Black, Henry R. Shinerfield, Marie Chelino. Maternal characteristics associated with the vaccination of young children. Pediatrics, 2003; 111: 1215-1218.

Elliott C, Farmer K. Immunization status of children under 7 years in the Vikas Nagar area, North India. Child Care Health and Development, 2006; 32: 415-421.

Fatima. R .Rahji and Chizoma .M. Ndikom. Factors Influencing Compliance with immunization Regimen among Mothers in Ibadan, Nigeria. IOSR Journal of Nursing and Health Science, 2013; 2 (2); 01-09.

Félicitée, N.D., Christiane, T., Roger, D., Sandra, T., Stève, F.W.D., Andreas, C., Innocent, K. and Marie, K. Factors Influencing Routine Vaccination of Children of Mothers Live-Stock Retailers in the Markets of Yaoundé. World Journal of Vaccines, 2016; 6: 23-33.

Fikree FF, Pasha O. Role of gender in health disparity: the South Asian context. BMJ, 2004; 328: 823-826.

Filmer D, King EM, Pritchett L. Gender disparity in South Asia: comparisons between and within countries. Policy Research Working Paper No. 1867. Washington, DC: World Bank, 1998.

Gaudin S, Yazbeck AS. Immunization in India 1993-1999: Wealth, gender, and regional inequalities revisited. Social Science and Medicine, 2006; 62: 694-706.

Gherardi E. The Concept of Immunity. History and Applications. Immunology course Medical School, University of Pavia. (ONLINE). Available

at: http://en.wikipedia.org/wiki/Immunity_(medical)\#cite_ref-Silverstein_2-0 (Accessed 2nd August 2016). 
Jamil K, Bhuiya A, Streatfield K, Chakrabarty N. The immunization programme in Bangladesh: impressive gains in coverage, but gaps remain. Health Policy Plan, 1999; 14: 49-58.

John Lekan Oyefara. Mothers' Characteristics and Immunization Status of Under-Five Children in Ojo Local Government Area, Lagos State, Nigeria. SAGE Open, 2014: 1-10.

Mabrouka A.M. Bofarraj. Knowledge, attitude and practices of mothers regarding immunization of infants and preschool children at $\mathrm{Al}$ Beida City, Libya 2008. Egypt J Pediatr Allergy Immunol, 2011; 9(1): 29 34.

Malini Kar, Reddaiah VP, Shashi Kant. Primary immunization status of children in slum areas of South Delhi - The challenges of reaching the urban poor. Indian J Community Med, 2001; 26(3): 151-154.

Moulton LH, Rahmathullah L, Halsey NA, Thulasiraj RD, Katz J, Tielsch JM. Evaluation of non-specific effects of infant immunizations on early infant mortality in a southern Indian population. Tropical Medicine of International Health , 2005; 10(10): 947-55.

Nath B, Singh JV, Awasthi S, Bhushan V, Kumar V, Singh SK. KAP study on immunization of children in a city of North India - A 30 cluster survey. Online J Health Allied Sci, 2008; 7: 2.

Nisar N, Mirza M, Qadri MH. Knowledge, Attitude and Practices of mothers regarding immunization of one year old child at Mawatch Goth, Kemari Town, Karachi. Pak J Med Sci, 2010; 26(1): 183186.

Omer Qutaiba B Al-lela, Mohd Baidi Bahari, Harith Khalid AlQazaz, Muhannad RM Salih, Shazia Q Jamshed and Ramadan M Elkalmi. Are parents' knowledge and practice regarding immunization related to pediatrics' immunization compliance? a mixed method study. BMC Pediatrics, 2014; 14: 20.

Pande PR, Yazbeck SA. What's in a country average? Wealth, gender, and regional inequalities in immunization in India. Social Science and Medicine, 2003; 57: 2075-2088.

Peter M Harrington, Catherine Woodman, William F Shannon. Low immunization uptake: Is the process the problem?. J Epidemiol Community Health, 2000; 54: 394-400.

Phouphenghack K, Kamsrichan W, Vorakitpokatorn S: Knowledge and perception of mothers about immunization of children under 3 years of age in the Saythany District, Vientiane. Lao PDR J Public Health, 2007; 5 (3): 107-115.
Prusty RK, Kumar A. Socioeconomic Dynamics of Gender Disparity in Childhood Immunization in India, 1992-2006. PLoS ONE, 2014; 9 (8): e104598.

Qidwai W, Ali S, Ayub S: Knowledge, attitude and practice regarding immunization among family practice patients. J Dow Univ Health Sci, 2007; 1 (1): 15-19.

Shah B, Sharma M, Vani S. Knowledge, attitude and practice of immunization in an urban educated population. Ind J Pediatr, 1991; 58 (5): 691-695.

Singh PK. Trends in Child Immunization across Geographical Regions in India: Focus on Urban-Rural and Gender Differentials. PLoS ONE, 2013; 8 (9): e73102.

Smith MJ, Woods CR, Marshall GS. Parental vaccine concerns in Kentucky. J Ky Med Assoc, 2009; 107: 342-349.

Soundarya Mahalingam, Abhijna Soori, Pradhum Ram, Basavaprabhu Achappa, Mukta Chowta, Deepak Madi. Knowledge, attitude and perceptions of mothers with children under five years of age about vaccination in Mangalore, India. Asian Journal of Medical Sciences, 2014; 5 (4): 52-57.

Streatfield K, Singarimbun M, Diamond I. Maternal education and child immunization. Demography, 1990; 27: 447-455.

Vilas RM, Hrishikesh Khadilakar, Rajesh NL, Umesh SJ, Sonali GC. Assessment of Sociodemographic Factors Affecting Immunization Status of Children in Age Group of 12-23 Months in a Rural Area. Indian Medical Gazette, 2013: 164-169.

\section{How to cite this article:}

Mugada V, Chandrabhotla S, Kaja DS, Machara SGK. Knowledge towards childhood immunization among mothers \& reasons for incomplete immunization. J App Pharm Sci, 2017; 7 (10): 157-161. 